\title{
THEORIES OF INTERPRETATION IN THE LAW OF CONTRACTS
}

\author{
MARJoRTE GrENE*
}

I

The rules concerning the construction of contracts are so well established as to require but brief attention. The object of construction is to ascertain the intention of the parties. That intention is to be determined from the language used in the instrument and not from any surmises that the parties intended certain conditions which they failed to express. Where there is no ambiguity in the language used, from that, and that alone, may the intention of the parties be gathered. ${ }^{x}$

In the construction of contracts for the purpose of ascertaining the intention of the parties the court will endeavor, by extrinsic evidence of such facts as the parties had in view, to place itself as nearly as possible in their position, so that it may understand the language used in the sense intended by them. ${ }^{2}$

$\mathrm{I}^{\mathrm{N}}$

N THE first of these two statements, it is said to be the object of the court to discover the intention of the parties. On the other hand, that intention is to be determined solely "from the language used in the instrument.". 3 But by reason of the abstractive nature of language any writing is bound to express actual intent with some degree of inadequacy. All meanings, as Wigmore says, are in some manner "subjective and personal" ; ${ }^{4}$ and it is always true in some sense-if it is actual intent we are after-that the parties have "themselves locked up the idea in the words" and so "themselves must furnish the key to unlock it." Why, then, if it is looking for motive and intention, does the court exclude all evidence but that of the writing itself, which is necessarily inadequate evidence of motive and intention? It looks as if, as Williston puts it, "the court is endeavoring to find as a controlling factor what ... may be wholly ineffectual" or as if the court is declining to use the means of

* Instructor in Philosophy, University of Chicago.

× Domeyer v. O'Connell, $3_{4}$ Ill. 467, 470, 4 N.E. (2d) 830, $83^{2}$ (I936).

2 Weger v. Robinson Nash Motor Co., 340 Ill. 8I, 9I, I72 N.E. 7, II (I930).

3 See also: Green v. Ashland State Bank, 346 Ill. I74, I82, I78 N.E. 468 (r93I); Emerich Outfitting Co. v. Siegel Cooper and Co., 237 Ill. 6ro, 86 N.E. Ito4 (Ig08); Sigsworth v. McIntyre, 18 IIl. I26, x27 (1856); Massie v. Belford, 68 Ill. 29o, 29r (1873); The Western and Southern Indemnity Co. v. Industrial Comm'n, 366 Tll. 240, 242, 8 N.E. (2d) 644 (I937); Mittel v. Karl, I33 Ill. 65, 7I, 24 N.E. 553 (I89o); Riggin v. Love, 72 Ill. 553, 556 (1874); City of Alton v. Illinois Transit Co., I2 Ill. 37, 56 (r850); Pool v. Blakie, 53 Ill. 495, 500 (I870); 3 Williston, Contracts $\S 6$ ro (rev. ed. 1936 ).

${ }^{4} 5$ Wigmore, Evidence $\$ 2462$ (2d ed. $x_{923}$ ).

$s I d$., at $\$ 2465$.

${ }^{6} 3$ Williston, Contracts $\S 6$ ro (rev. ed. 1936 ). 
finding what it is presumably endeavoring to find. Nor is the discrepancy alleviated by the use of phrases like "expressed intent"' or "the true intent of the contracting parties as expressed in the language of the policy." The court is either looking for intent or it is not; and if, as the case cited above declares, it is looking for intent, there is at least on the face of it a certain oddity in the exclusion of evidence relevant to the determination of intent.

As between the first and second statements, moreover, a second difficulty emerges. According to one series of opinions it is a primary rule of interpretation that, unless a writing is ambiguous, construction is to be based solely upon the writing itself without the aid of any extrinsic evidence. In another group of cases, deriving from equally well-established precedent, it is said that "the court will endeavor, by extrinsic evidence of such facts as the parties had in view, to place itself as nearly as possible in their position, so that it may understand the language used in the sense intended by them." But the two doctrines are manifestly incompatible. In the one case the court takes the language of a writing at its face value, admitting no extrinsic evidence for the purpose of determining its meaning. In the other the court attempts to reconstruct the position of the parties at the time and place of the writing, admitting evidence of surrounding circumstances for the purpose of determining such meaning as would attach to the writing at that time and place and under those attendant circumstances.

It would appear, then, that at least in two respects the primary rule concerning the interpretation of contracts needs clarification. (I am not concerned here with the various subordinate rules of construction, such as the rule that every part of a contract should be given effect if possible, etc. Such problems as those principles present are wholly dependent upon the issue involved in the statement of the primary rule or rules.) In the first place, the relation of construction to the determination of actual intent needs to be re-examined. Is it true that "in construing a written

I Ibid.

${ }^{8}$ The Western and Southern Indemnity Co. v. Industrial Comm'n, 366 Ill. 240, 242, 8 N.E. (2d) 644 (1937).

9 This series of cases rests ultimately on the authority of Doyle v. Teas, 4 Scam. (III.) 202, 255 ( 1843 ). "We find the courts, in all cases, endeavoring by extrinsic evidence, to place themselves, as far as possible, in the position of the contending parties, so that they may understand the language used, in the sense intended by the parties using it." $C f$. Field v. Leiter, II 8 Ill. I7, 26, 6 N.E. 877 ( 1886 ); Whalen v. Stephens, I93 III. I2I, I34, 6I N.E. 921 (I9OI); Conway Co. v. City of Chicago, 274 Ill. 369, 374, Ir3 N.E. 703 (rgr6); McLean County Coal Co. v. City of Bloomington, 234 Ill. 90, 96, 84 N.E. 640 (rgo8). 
instrument the great object is to arrive at the intention of the parties"? ? $^{\circ}$ Or does the occurrence of that aim coincide, as is suggested in Benjamin v. $M c$ Connell ${ }^{\mathrm{Ix}}$ with the occurrence of ambiguous language in the writing to be interpreted? And if, as most of the cases indicate, the former maxim holds, though we shall have to examine its meaning more closely later, what is the basis for the exclusion of evidence of intention? Secondly, if extrinsic evidence is excluded in construing a contract, what becomes of the principle that the court will "endeavor to place itself in the position of the parties"? In some cases, it is true, the latter rule is stated as secondary, i.e., as functioning only when the language of the contract is ambiguous.12 In other opinions, however, it is clearly stated that the court will endeavor in all cases to reproduce the circumstances in which the contract was executed $;^{13}$ and in still other instances, it is not clear from the language of the opinion whether the rule is operating as a primary or an auxiliary principle. ${ }^{14}$

\section{II}

When, as in the cases cited, it is stated, first, that the object of construction is to ascertain the intent of the parties, and, secondly, that the court will exclude extrinsic evidence bearing on such intent, it is sometimes added that the restriction involved in the second statement is drawn in order to save the parol evidence rule, i.e., "the well settled rule that prior or contemporaneous conversations are not admissible to contradict or vary the terms of a written agreement." ${ }^{25}$ It is said that:

so McLean County Coal Co. v. City of Bloomington, 234 IHl. 90, 97, 84 N.E. 640 (Igo8); Peoria and Pekin Union Ry. Co. v. Tamplin, I56 Ill. 285, 40 N.E. 960 (I895).

II 4 Gilm. (III.) 536,545 ( 1847 ).

${ }^{12}$ Barrett v. Stow, ${ }_{5}$ Ill. 423,424 (1854): "Upon this subject the contract as written is not specific, and in order to understand the meaning of the parties, it is proper to ascertain such extrinsic facts as the parties had in view at the time the contract was made, in order to ascertain their true meaning." Street v. Chicago Wharfing Co., I57 Ill. 605, 6I3, 4I N.E. Iro8, III2 (I895).

${ }_{3}$ Doyle v. Teas, 4 Scam. (Ill.) 202, 255 ( $x 843$ ). Conway Co. v. City of Chicago, 274 Ill. 369, 374, II3 N.E. 703 ( $19 \times 6)$ : "In construing contracts, courts will always seek to discover and give effect to the intention of the parties, and for the purpose of ascertaining such intention will endeavor to place themselves in the position of the contracting parties, so that they may understand their language in the sense in which they used it." $C f$. Hoffer Oil Corp. v. Hughes, I6 S.W. (2d) 90I, 904 (Tex. Civ. App. I929): "Whether the language of the contract be ambiguous or not, in ascertaining the intention of the parties, the surrounding facts and circumstances and the purposes sought to be accomplished by its making should be considered."

$x_{4}$ McLean County Coal Co. v. City of Bloomington, 234 IIl. 90, 96, 84 N.E. 640 (Ig08).

is Tyer v. Caldwell, II4 Okla. I3, I5, 242 Pac. 760, 76r (I925). 
while the intention of the parties is sought, it can be found only in their expression in the writing. In effect, it is not the real intent but the intent expressed or apparent in the writing that controls. The obligation of a contractor depends upon his expressed, not his actual intention... . The parties are bound by the language used regardless of their intent. The terms of the writing are exclusive, and, therefore, a contract may have a different meaning from that which either party supposed it to have. . . Otherwise, there would be a disregard of the well settled rule forbidding the introduction of parol evidence to contradict the terms of a written contract. ${ }^{26}$

As a matter of fact, it is of course not "written" but "integrated" agreements for which the parol evidence rule operates. If an agreement is written but not integrated it is beyond the scope of the rule; and should an agreement be integrated though not written (a theoretical though unlikely possibility) it would come within the scope of the rule. An agreement is integrated, according to the definition of the Restatement, "where the parties thereto adopt a writing or writings as the final and complete expression of the agreement." ${ }^{\prime 7}$ What determines integration, therefore, is not some particular kind of writing, but the assent of the parties to this writing (or, in the rare case, these spoken words) as the full and complete expression of their agreement. "If such assent is manifested the writing may be a letter, telegram, or other informal document." The parol evidence rule, then, is a rule applying to the class of integrated agreements. If, therefore, the exclusion of evidence of actual intent is effected to save the parol evidence rule, such exclusion will evidently apply only to the class of integrated agreements, to which the parol evidence rule applies; and in all other cases the court will be free to admit evidence of actual intent-if such intent be in fact the object of its search.

It would appear, therefore, that there are in fact two primary rules for the interpretation of contracts: one which holds for all cases to which the parol evidence rule applies and one holding for all other cases. It would seem, further, from the weight of authority in the cases, that in the former class the primary rule operates to the exclusion of extrinsic evidence where the meaning of the instrument is clear, but gives way to a subordinate rule, admitting such evidence, when the language of the writing is ambiguous. Such a multiple standard theory appears on the face of it to offer both the source and the solution of our difficulties; and an examination of the theory as Williston formulates it should shed some light, direct or indirect, on both the questions of the preceding section.

${ }^{16}$ Corn Exch. Nat'l Bank \& Trust Co. v. Taubel, Ir3 N.J.L. 605, 609, 775 Atl. 55, 57 (I935) (italics added). Cf. Kentucky Wagon Co. v. People's Supply Co., 77 S.C. 92, 57 S.E. 676 (1906). 604 .

${ }_{17}$ Rest., Contracts, $\S 228 ; 3$ Williston, Contracts $\$ \S 631-3$ (rev. ed. I936). Cf. id., at $\$ \S 603$, 
Our immediate question is: Are there in fact two clearly separated classes of contracts to which two clearly distinguishable standards of interpretation apply? And is there within one of those standards a clear distinction between a rule for the construction of clear and unambiguous language and a rule for the construction of language that is not clear and unambiguous?

It should be added that the present question hinges primarily on that aspect of the parol evidence rule which concerns ambiguity. Neither the problem of the relation of integration to the admissibility of evidence of collateral agreements nor the problem of the relation of integration to questions of mistake is material to the present issue. It is apparently the principle that where there is a writing "the province of construction lies wholly within the domain of ambiguity" tion between two classes of cases-or conversely, it is the exclusion of parol evidence in cases where the meaning of the writing is "clear" that seems to necessitate the establishment of a special standard for agreements concerning which such exclusion may be effected. What Wigmore calls the "clear-meaning" rule ${ }^{\mathrm{x}}$ as opposed to the rule on collateral agreements or mistake is, therefore, the only fraction of the parol evidence rule under consideration in the present paper; and by "parol evidence rule" I shall here mean the rule that parol testimony (or testimony of prior or contemporaneous agreements) is not admissible to alter the plain meaning of an integrated writing. According to the multiple standard theory, contracts are divided with reference to interpretation into two classes. "In one division must be put not only formal contracts such as sealed instruments and negotiable paper, but also contracts or agreements where the parties have manifested assent not merely to the terms of their agreement but to a writing or other fixed symbol as a memorial or integration of that agreement. In this class must also be put contracts of which the law requires a written memorandum. .... In a second division must be put all other contracts."20 To the second class a standard of reasonable expectation is applied, ${ }^{2 x}$ and to the first class a standard of limited usage, ${ }^{22}$ except that where the result of applying that standard is ambigu-

${ }^{18}$ Norfolk Motor Exch. v. Grubb, ${ }_{52}$ Va. 47I, 478, I47 S.E. 214, 216 (I929).

I9 5 Wigmore, Evidence $\$ 2462$ (2d ed. I923).

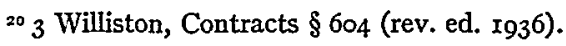

2x "A standard of reasonable expectation, which would attach to words or other manifestations of intention the meaning which the party employing them should reasonably have apprehended that they would convey to the other party." Id., at $\S 603$; Rest., Contracts $\$ \S 227$, 233 (I932).

22 "A standard of limited usage, which would attach the meaning given to language in a particular locality, or by a sect or those engaged in a particular occupation, or by an alien 
ous the standard otherwise restricted to the second class becomes applicable here. ${ }^{23}$

Presumably, since one standard would be easier to administer than two, there is some reason, in principle or precedent, for the multiplication of standards; and, as I have suggested, it is primarily the authority of the parol evidence rule that seems to provide that reason. Williston says:

Doubtless it would be simpler if one standard of interpretation could be asserted for all manifestations of intention forming contracts or relating to their formation, but the parol evidence rule makes it clear that this cannot be done. This rule denies effect, where there is a writing to which the rule is applicable, to certain manifestations of intention which are operative in cases where the parol evidence rule is not applicable. It follows that there must be at least two standards by which the meaning of contracts or agreements must be tested. 24

Putting off for a moment the question where, if anywhere, within the class of all contracts the operation of the parol evidence rule effects a division, or what difference, if any, subsists between the standards operative in the sub-classes thus created, one may object, I think, that the above argument, in abstraction from the specific subject matter to which it is applied, is formally very uncertain. To be sure, the ultimate question is the practical one whether the results in two kinds of cases are so different as to demand a difference in the formulation of the principles implied. Still, the multiplication of rules, where such multiplication is formally unnecessary, is merely confusing-so that the multiplication, if it is to be accepted, needs logical justification as against the simpler and hence more convenient alternative. And the lack of such justification would seem to indicate the inconvenience (though not of course the impossibility) of such a plural rule compared with the simpler formulation. With this pragmatic issue in mind, then, we may inquire into the logic of the present situation. If one is looking for a rule covering a certain operation in a given field, and one discovers that there is a related rule relevant to the operation in question which restricts, within a certain portion of the field, the material on which the rule sought might operate, one infers that

population or those using a local dialect." 3 Williston, Contracts $\$ \S 603,604$ (rev. ed. I936); Rest., Contracts $\$ \$ 227,230$ (I932).

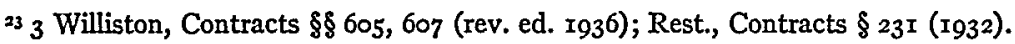

${ }^{24} 3$ Williston, Contracts $\$ 603$ (rev. ed. I936). This statement is added in the revised edition; but it seems to crystallize in explicit form a connection implicit in the whole discussion. $C f$. the argument of $\S 60 \%$, where two kinds of cases furnishing "exceptions" to the standard of reasonable expectation are given: "If the promisor's justifiable belief were the standard which the law adopted it would be applicable to every case. That it is not is evident from the two exceptions mentioned." Formally this argument is identical with or closely analogous to that cited above. 
the general rule becomes under such and such circumstances (namely under the circumstances delimiting the portion of the field to which the correlative rule applies) totally or partially inoperative. But solely from the existence of such exceptions in the operation of a rule is one bound to infer that there is no such general rule for the field in question, or that there are two totally separate rules for the two sub-fields? Did one in fact so correlate difference in rule (or related rule) with rigid division of the field, one would have to set up at least a third division among contracts, corresponding to the cases (involving the use of codes, etc.) in which a mutual standard is accepted--as opposed to the standards both of reasonable expectation and of limited usage. Such cases may be limited in number, but they do constitute an exception; and if it is true that rules are universal for the members of the field they cover, in such fashion that where there is an exception there is necessarily a separate rule for the separate field thus created, then such a division would certainly be demanded. Williston does not, however, insist on the separation from all other agreements of agreements effectively using a mutual language; and it therefore seems fair to infer that the parallel argument in the case of the parol evidence rule is insufficient, taken alone, to necessitate the division of the total class of contracts into two sub-classes differentiated by their subjection to different standards of interpretation. It might just as well be the case that the parol evidence rule delimits a set of excepted cases under a general principle-just as the occurrence of ambiguity is said to do under the standard applied to integrated agreements. To be sure, Williston's statement of the variant results that actually follow from the application of his two standards constitutes his strongest argumentand I shall consider it more fully below. At present I am concerned, however, with the first and formal argument; and my point is simply that the necessity for a dual standard does not follow analytically from the mere existence of a rule "excluding certain manifestations of intention" in a certain class of cases. So far, then, logic does not, as Williston suggests, compel us to choose the more complex formulation. And, unless we find some other reason, convenience would therefore dictate the adoption of a single standard.

It is further asserted, however, that between the class of agreements to which the parol evidence rule does not apply and the class to which it applies there is a material difference with respect to the relation of the words used to the parties using them and the objects designated. It is held, in other words, that in these two groups of cases language plays two 
different roles and is therefore to be interpreted by two correspondingly divergent standards.

In an ordinary oral contract or one made by correspondence, the minds of the parties are not primarily addressed to the symbols which they are using; they are considering the things for which the symbols stand. Where, however, they incorporate their agreement into a writing they have attempted more than to assent by means of symbols to certain things, they have assented to the writing as the adequate expression of the things to which they agree. 25

But on the other hand, it has been said that "in every case, the words must be translated into things and facts by parol evidence, ${ }^{, 26}$ or that the process of "turning signs and symbols into their equivalent realities" is always "to some extent" a necessary one; ;7 and thus it would appear that symbols have in no case an intrinsic significance apart from their designative function. Such statements, as the preceding one (that words must be translated into things or signs turned into realities), are, it is true, inaccurate; for Blackacre has never been to court, although its designation, "Blackacre," appears there frequently. But surely it is true that the court, having before it certain symbols in a certain language, endeavors in all cases to determine the rules of that language - whether of country, trade, region or even, in some cases, individual - with precision and completeness sufficient to guarantee with a reasonable degree of certainty the identification by a reasonable person using that language of the objects or events designated by the symbols in question. The court neither brings Blackacre into the courtroom nor goes to Blackacre; but it does attempt to connect "Blackacre" with a set of descriptive words sufficiently clear and complete to fulfill the following condition: that if a reasonable person should hear and understand the conjunction of that set of descriptive words with the word "Blackacre" and should then, perceiving a place fitting the description, call it Blackacre, the place so designated would very probably be Blackacre. "The minds of the parties" may, indeed, have been focused somewhat more consciously, in the case of an integrated as against a nonintegrated agreement, upon linguistic as opposed to factual problems; but the minds of the parties are no more perceptibly in the courtroom than is Blackacre. What the court has before it in any case is not a mental process but a set of sentences-whether in an integrated writing, a nonintegrated writing or writings, or a report of spoken words; and the task of interpretation in any of those cases consists in determining univocally,

${ }^{25} 3$ Williston, Contracts $\S 606$ (rev. ed. I936).

${ }^{2}$ Holmes, J., in Doherty v. Hill, 144 Mass. 465, 468, ir N.E. 58I, 582 (I881).

${ }^{27}$ Cardozo, J., in Marks v. Cowdin, 226 N.Y. I38, 143, I23 N.E. r39, r4I (r919). 
in the given language, rules for the correlation of the symbols used with the objects they designate. As regards the relation of symbols to things symbolized there is no material difference between an integration and any other group of sentences; and the semantical argument, like the formal, appears insufficient to establish the need for a multiple standard of construction.

But even if the validity of both the preceding arguments were granted -if one admitted the necessity of dividing all contracts, with respect to standards of interpretation, into two classes, a division based on the demand of the parol evidence rule would not correspond to the division that Williston actually makes. Yet it was the authority of the parol evidence rule, as we have seen, that was said to demand the division.

The parol evidence rule applies to integrated agreements ${ }^{28}$ and a division of contracts into two classes should, if based on the scope of that rule, include in one sub-class all integrated agreements and only integrated agreements, and in the other sub-class no integrated agreements but all non-integrated agreements. Actually, however, the line is drawn between the class of all agreements which are either integrated or such that a written memorandum is required by law and the class of all other agreements. ${ }^{29}$ The first class thus contains some non-integrated agreements, while the second class does not contain all non-integrated agreements. The criterion of "integration," it is true, is not precisely determined. Although the definition of an integrated agreement as one "where the parties thereto adopt a writing or writings as the final and complete expression of the agreement"30 seems at first sight reasonably clear, Williston's discussion of "intent" as the criterion of integration appears to the present writer at least to leave very uncertain the location of the line or shadow of a line that is said to separate integrated contracts from all others..$^{3 x}$ But wherever the line apparently demanded by the parol evidence rule be drawn, it is clear that that line is not identical with the line drawn with respect to interpretation between two classes of contracts. For we are told explicitly that the memorandum required by the statute of frauds "need not necessarily be an integration or memorial of the contract"; ${ }^{32}$ and we are told explicitly that such memoranda are included with integrated agreements in the first class of contracts. The reason given, moreover, for such inclusion (that "the purpose of the law in requiring written (1932).

${ }_{28} 3$ Williston, Contracts $\S \S 63$ r, 633 (rev. ed. 1936 );Cf. $\S \S 603,604$. Rest., Contracts $\S 238$ ${ }_{29} 3$ Williston, Contracts $\S 604$ (rev. ed. 1936).
${ }^{30}$ Ibid.
${ }^{3 x} I d$., at $\S 633$.
${ }^{32} I d$., at $\S 604$. 
evidence can be satisfied only if the same standard is applied to memoranda under the statute as is applicable to written contracts") ${ }^{33}$ suggests very forcibly that policy rather than theory may dictate the division.

Nor do the cases cited by Williston fall into classes corresponding to a clear theoretical division. If the line between integrated and non-integrated agreements can be traced at all, it would certainly seem that an insurance policy is normally an integrated writing; but Bird v. St. Paul F. \& M. Ins. Co., ${ }^{34}$ Davis v. Highway Motor Underworiters ${ }^{35}$ and Granger ข. N.J.Ins. Co. ${ }^{36}$ are instances of insurance cases cited to illustrate the rule for "informal" contracts-that is, in Williston's use of "informal" in this context, for contracts which are neither integrated nor such that a written memorandum is required by law. The rule stated in those cases is, indeed, Williston's "informal" rule-the standard of reasonable expectation; but when a rule is enunciated in the context of a case belonging to the class to which that rule is said not to apply, its citation scarcely strengthens the argument. ${ }^{37}$ And conversely, there are citations for the other rule (as Logan-Long v. Roger Laudati) ${ }^{38}$ which seem very uncertainly to fall under the class of agreements integrated or requiring written memoranda. Indeed, as we shall observe more closely below, the standards stated for the two classes resemble one another so closely that it is very possible (as in the instance of Clark v. Lillie) ${ }^{39}$ to cite the same opinion in illustration of both rules.

It looks, therefore, as if it could hardly be the parol evidence rule which necessitates the dual standard-since the classes to which the two standards are said to apply fail to correspond to the division effected by that rule.

The crux of Williston's argument, however, lies in his statement of the kinds of cases in which the results reached by applying the local standard differ from those reached by applying the standard of reasonable expecta-

33 Ibid.

34224 N.Y. 47 , 120 N.E. 86 (1918). ${ }^{35}$ I 20 Neb. 734, 235 N.W. 325 (193I).

${ }^{36}$ I08 Cal. App. 290, 29r Pac. 698 (r930).

${ }^{37}$ See also Danforth v. Chandler, 237 Mass. 518, 130 N.E. 105 (r921), a statute of frauds case here cited under the rule for the second class of contracts.

${ }^{38} 52$ R.I. 250 , 160 Atl. I99 (1932) cited by Williston as an example of the secondary rule that "the standard for oral agreements applies where integrated contracts appear ambiguous." The court there says: "First of all it should be noted that the letter does not purport to contain all the terms of the agreement." $C f$. Deutsch v. Pratt, $x_{49}$ Mass. 4I5, 420, 2I N.E. ro72, ro74 ( 1889 ), cited 3 Williston $\$ 606$ as an example of the principle that contracts of the first class exist even though the parties may attach different meanings to the language; Preston $v$. Luck, L.R. 27 Ch. D. 497 (1884).

${ }^{39} 39$ Vt. 405 (1867). 
tion-for unless there are important practical differences in the results actually issuing from the use of the two standards, the duality would certainly appear superfluous. He states:

The results reached by applying the local standard are the same as would be reached by applying the standard applicable where no memorial is made of the agreement, or apparent agreement, except in two cases-

(x) where there is such a justifiable difference of belief concerning the sense in which the parties used the words as would prevent the existence of a contract had the negotiations been informal.

(2) where the sense which the promisor reasonably supposed the other party would attach to his words is one which neither normal usage, nor local or technical usage justifies..$^{\circ}$

The second exception is clearly based on policy and presents no problem with regard to standards of interpretation. The mutual standard is arbitrarily excluded for reasons of policy operating from beyond the limits of any theory of interpretation. It is the first exception, then, that is crucial. Are there in fact cases in which "justifiable beliefs" of the parties sufficient to establish a contract "had the negotiations been informal" are rendered ineffective by the operation of the standard of limited usage? For the cases cited by Williston in this context the answer is clearly negative. In every case the contrast is made not between the "justifiable beliefs" of the parties as to the meaning of the language used and the usual or local meaning, but between their actual beliefs about such meanings and the beliefs they might reasonably have been supposed to hold. The contrast, in other words, is one between actual intention on the one hand and the meaning of language as a reasonable man would understand it on the other. It is not the justifiable beliefs of the parties but their actual beliefs which are ineffective - and those beliefs are ineffective just because they are not justifiable-that is, because the parties did not actually give to the words they used a meaning which could reasonably be given them. In the case most fully cited here it was said "that where a written agreement has been signed .... the fact that the plaintiff has put an erroneous construction upon it, and insisted that it included what it did not include, does not prevent there being a contract." $4 \mathrm{I}$ It is clear that it is here the actual understanding of the plaintiff which is contrasted to what he ought reasonably to have understood by the language used. The same contrast appears in every other case cited..$^{42}$ For instance, in Saveyer $v$. Hovey it

${ }^{40} 3$ Williston, Contracts $\S 607$ (rev. ed. 1936); Cf. §§ 606, 6 1о.

4I Preston v. Luck, L.R. 27 Ch. D. 497 (I884).

${ }^{42}$ Sawyer v. Hovey, 3 Allen (Mass.) 33I, 333 (I862), mistake of expression not proved clearly enough for reformation; Citizens' Tel. Co. v. Newport, I88 Ky. 629, 224 S.W. I87 
is said that "if parties understand an agreement differently, and neither of them makes known to the other his construction of it, and it is afterwards reduced to writing and duly executed, they are bound, in equity, as well as at law, by the terms of the written instrument, which in such cases is to be construed by the court." 43 Or again, in Woburn Nat'l Bank ข. Woods: "A party cannot escape the natural and reasonable interpretation which must be put on what he says and does, by showing that his words were used and his acts done with a different and undisclosed intention."44 And in Phillip v. Gallant Church, C.J., declared:

In the recent case of Smith v. Hughes, cited by the counsel for the defendant, Blackburn, J. lays down the correct rule which is, I think, applicable to this case. He says: "If, whatever a man's real intention may be, he so conducts himself that a reasonable man would believe that he was assenting to the terms proposed by the other party, and that other party upon that belief enters into the contract with him, the man thus conducting himself would be equally bound as if he had intended to agree to the other party's terms." 45

The above contrast, moreover, between actual intention and the meaning of language as a reasonable man would understand it (or expect it to be understood) is equally to be made in Williston's second class of contracts. For it is the standard of reasonable expectation, not an individual standard which is applied in such cases; and actual intent is there just as ineffective as in the first class of contracts. The rule is clearly stated in Clark v. Lillie:

The law will presume that the defendant meant what his language by its terms and under the circumstances in which it was used would fairly be understood to mean, and this presumption is a matter of law and not to be rebutted by proof that he intended something more or different which he made no attempt to express and which the plaintiff neither understood nor had reason to understand..$^{6}$

It is evidently true for all cases, therefore, and not only, as Williston holds, for a restricted group of cases, that "a contract may be created

(1920); Deutsch v. Pratt, I49 Mass. 415, 2x N.E. 1072 (1889); Mechaber v. Pittle, 270 Mass. I93, r7o N.E. $5^{2}$ (1930), individual or mutual standard does not control; Illinois Fuel Co. v. Mobile Co., 3 I9 Mo. 899, 920, 8 S.W. (2d) 834 (Ig28) words apparently creating joint or joint and several obligation not effectual by "practical construction"; Woburn Nat'l Bank v. Woods, 77 N.H. 172, 89 Atl. 49r (1914); Phillip v. Gallant, 62 N.Y. 256 (I875); Sanders v. Cooper, II5 N.Y. 279, 22 N.E. 212 ( 1889 ), action on insurance policy as if reformed improper; suit necessary; Brainerd v. N.Y. Central Railroad Co., 242 N.Y. x25, x5I N.E. I52 (1926); Johnston v. Patterson, II 4 Pa. 398, 6 Atl. 746 ( 1886 ); Schunecht v. Robers, I92 Wis. 275, 212 N.W. 657 (I927). The only case in which the contrast is not clear is Henrietta Mills v. Comm'r, 52 F. (2d) 93 I (C.C.A. $4^{\text {th }}$ 193I). The question in that case, however, was one of taxation, not contracts, and it is not strictly comparable with the other cases.

43 Allen (Mass.) 33r, 333 (I862).

4562 N.Y. 256,263 (I875).

${ }_{44} 77$ N.H. 172, I75, 89 Atl. 49r, 492 (I9r4).

${ }^{46} 39$ Vt. 405 (1867). 
though each party attached a different meaning to the language used, if he had no reason to suppose that his own meaning was not shared by the other party." 47 Williston does insist, it is true, that in the class of agreements including integrations contracts may exist where parties attach different meanings to the language "no matter how reasonable may have been the belief of each." ${ }_{48}^{8}$ But this qualification seems to me to be flatly contradicted by the qualification of the sentence quoted just above, which, deprived of its double negative, reads: "A contract may be created though each party attached a different meaning to the language used, if he had reason to suppose that his meaning was shared by the other party"49-if, in other words, the standard of reasonable expectation could be effectively applied to the language used. But a case, on the other hand, in which the reasonable (as opposed to the actual) beliefs of the parties with regard to the meaning of the terms used by them should prove ineffective and in which at the same time there should be room for a reasonable interpretation by the court seems practically and logically very close to inconceivable. To talk about a man's "justifiable beliefs" and to talk about conduct on his part such that "a reasonable man would believe that he was assenting to the terms proposed" seems to me clearly to be talking about one and the same norm in a slightly different metaphor; and to render the first factor ineffective while giving effect to the second would seem to mean enforcing at one and the same time two directly contradictory principles.

There is, of course, the possibility, as cases like Domeyer v. O'Connell ${ }^{\circ}$ suggest, that it is more than simply evidence of actual intent which, for integrated contracts, the parol evidence rule operates to exclude. Certainly some of the cases insist on the exclusion of all extrinsic evidence where the language of a writing is "plain."

When the question is one of the interpretation of a contract, entire in itself in all particulars, it is only when different inferences may fairly be drawn as to the meaning and effect of the written language used, that the relation of the parties and the surrounding circumstances are to be considered by the jury in arriving at their intention..$^{5 x}$

It is clear, however, that if no evidence whatsoever of surrounding circumstances be admitted, it is the normal as opposed to the local standard which automatically becomes effective in every case-since evidence of

${ }^{47} 3$ Williston, Contracts $\S 606$ (rev. ed. 1936 ).

${ }^{8}$ Ibid.

${ }^{49} \mathrm{Ibid}$. (Italics added).

${ }^{50} 3^{6} 4$ IIll. 467,4 N.E. (2d) 830 (1936).

${ }^{5}$ St. Regis Paper Co. v. Hlubbs \& Hastings Paper Co., 235 N.Y. 30,36 , I38 N.E. 495,496 I923). 
surrounding circumstances is necessary for the determination of trade or local meaning. On the face of it the phrase "white selvage" denotes, quite unambiguously, white selvage, and unless evidence of usage be admitted it cannot be interpreted as designating what in non-trade terms would be dark gray selvage..$^{52}$ If no extrinsic evidence be admitted to "alter plain meanings," a case like Kentucky Wagon Co. v. People's Supply Co.,53 in which normal as opposed to local meaning is insisted on, is clearly right. If, on the other hand, extrinsic evidence be admitted, not to alter meanings but to determine them (and both Williston and the Restatement declare emphatically for its admission), ${ }^{54}$ the line between the alleged two standards fades on two scores. For it may be maintained, first, as in Marks v. Cowdin, that the admissibility of extrinsic evidence is a matter of degree, not of kind: "Parol evidence bearing on actual intent is a limiting case of extrinsic evidence which is excluded on grounds of policy." 55 And it may be held, secondly, that although as a matter of policy the explicit exclusion of evidence of intent may perhaps be peculiarly important in the first class of contracts (where there is an integration or where a writing is required by law), such evidence is actually irrelevant for any type of agreement. ${ }^{6}$ For in the second class of agreement it is a standard of reasonable expectation, not of actual expectation, that is applied; and the actual intention of the parties with regard to the lan-

${ }_{52}$ Mitchell v. Henry, L.R. I5 Ch. D. I8I (I880).

${ }^{53} 77$ S.C. 92,57 S.E. 676 ( 1906 ): "Conceding it was the usual practice of insurance companies in general to write policies containing the three-four clause, such practice could not be shown for the purpose of contradicting words in agreements entered into by third parties, which are free from ambiguity or equivocation; and in their ordinary and usual acceptation have but one meaning, as in the case under consideration. This would infringe upon the well settled doctrine that parol testimony is inadmissible for the purpose of contradicting the terms of a written instrument."

${ }^{54} 3$ Williston, Contracts $\S 629$ (rev. ed. 1936); Rest., Contracts $\S 230$. Cf. 5 Wigmore, Evidence $\$ 2470$ ( $2 \mathrm{~d}$ ed. 1923).

${ }^{55} 226$ N.Y. I38, ${ }_{433}$, I23 N.E. I39, $\mathrm{r}_{40}$ ( $\mathrm{rg}$ Ig): "In thus identifying the position we are not importing into the contract a new element of promise. We are turning signs and symbols into their equivalent realities. This must always be done to some extent, no matter how many are the identifying tokens. In every case, the words must be translated into things and facts by parol evidence. (Holmes, J., in Doherty v. Hill, supra, p. 468; Mead v. Parker, supra, p. 415: 4 Wigmore on Evidence, sec. 2454). How far the process may be extended is a question of degree (Doherty v. Hill, supra, p. 469). We exclude the writing that refers us to spoken words or promise. We admit the one that bids us ascertain a place or a relation by comparison of the description with some 'manifest, external, and continuing fact' (Doherty v. Hill, supra, p. ${ }_{469}$ ). The statute must not be pressed to the extreme of a literal and rigid logic. Some compromise is inevitable if words are to fulfill their function as symbols of things and of ideas."

${ }^{56}$ See section III infra; Holmes, The Theory of Legal Interpretation, I2 Harv. L. Rev. 4I 7 (1899). Evidence of actual intention is relevant, Holmes maintains, only (as in some cases in the interpretation of will) where it bears on the objective meaning of the language. 
guage they use may-even though evidence of it be forbidden only for a restricted group of cases-prove just as ineffective in any other case as it does in those cases in which the parol evidence rule is said to operate. The rule, in other words, becomes trivial in the sense that it excludes, for a certain class of cases (and a class which, as was suggested above, is at best very uncertainly delimited) a factor which is practically ineffective or irrelevant in all cases.

From all these considerations it would appear that a clear line between two classes of contracts governed by distinct standards is difficult to draw. But the alleged relation, in the first class of contracts (in which there is an integration or a writing is required by law) between a primary and a secondary standard is equally perplexing. Where, we are told, (and only where) the application of a standard of limited usage produces an "ambiguous" result, the standard of reasonable expectation is applied.57 It thus appears that having admitted enough evidence of surrounding circumstances to make a local or trade or technical meaning effective we fall back on a vestige of the "clear meaning" rule for another distinction apparently as rigid as the one discarded. In view of this distinction it becomes necessary to inquire into the meaning of "plain meanings" in order to ascertain at what point the standard of reasonable expectation is said to re-enter. As an instance of that standard Williston considers in this connection the rule that "when the terms of an agreement have been intended in a different sense by the parties to it, that sense is to prevail against either party in which he had reason to suppose the other understood it." ${ }^{8}$ In Inman Manufacturing Co. v. Cereal Co. (quoted at length by Williston) McLain, J., in order to elucidate the meaning of the rule as it occurs in the Iowa code, cites a long series of cases illustrating its use as a common law rule. He concludes:

An examination of the cases already cited will show that the common-law rule has been limited in its application to cases in which there has been a controversy arising under a contract in ambiguous language, or in which some mistake or uncertainty has appeared with reference to the subject-matter to which the language is sought to be applied. The rule has never been recognized as authorizing the interpretation of plain and unambiguous language of a written instrument in accordance with any other meaning than that indicated by the words used in the instrument..$^{59}$

Similarly, the court declared in another Iowa case:

The principle that, when the terms of an agreement have been intended in a different sense by the parties, that sense is to prevail against either party in which he had

${ }^{57} 3$ Williston, Contracts $\S 607$ (rev. ed. 1936); Rest., Contracts $\S 23$ (1932).

${ }^{58} 3$ Williston, Contracts $\S 607$ (rev. ed. 1936).

${ }^{9}$ I33 Iowa 7x, 75, IIo N.W. 287, 288 (rgo7). 
reason to suppose the other party understood it, has no application to contract promises couched and framed in plain and unambiguous words. $0^{60}$

But what are "plain and unambiguous words"? Outside court rooms and legal treatises words are usually said to be unambiguous when a reasonable person acquainted with the natural language in which the words occur (in this case English) would without hesitation interpret them in the same way in which any other reasonable person similarly equipped would interpret them. That is, the words in a writing are unambiguous when simply by their occurrence in the document they suggest rules of application so clearly that no alternative to the one obvious meaning presents itself. Suppose, however, we accept that interpretation of the phrase "plain and unambiguous words." We should then assent, I suppose, to dicta like that of Strong v. Carver:

It is a familiar principle that, where a written contract is ambiguous and of doubtful meaning, proof of the conditions and circumstances under which it was made, and of the facts to which it relates, may be introduced to apply it properly to the subject-matter, and to ascertain the true meaning of its language as it was used by the parties. .... But this rule applies only where the meaning of the writing would otherwise be doubtful. It cannot be applied to contradict the plain meaning of the words. ${ }^{6 x}$

In other words, we are back with the rule for the exclusion of all extrinsic evidence where the meaning of words appears unambiguous on the face of the document alone - and it becomes necessary, as was indicated above, to give effect exclusively to the normal meaning of language as opposed to any special meaning which might be shown by evidence of usage or other "surrounding circumstances."

If, on the other hand, as Williston agrees with the majority of more recent cases in insisting, ${ }^{62}$ evidence of usage is always to be admitted, the word "unambiguous" is evidently not to be taken as meaning plain in the context of the writing alone, but plain in the light of the surrounding circumstances. It becomes necessary, that is, to add a further qualification to the common-sense definition of "unambiguous words." Words are said to be unambiguous when a reasonable person, acquainted with the natural language in which the words occur, and with the circumstances (of professional, geographical, social, or in some cases even individual linguistic custom) under which the words were used, would without hesitation interpret them in the same way in which any other reasonable person similarly equipped would interpret them. That

6o Comptograph Co. v. Burroughs, I79 Iowa 83 , Ior, I59 N.W. 465,474 (IgI6).

${ }^{6 x}$ I97 Mass. 53, 59, 83 N.E. 328, 330 (1907).

${ }^{62} 3$ Williston, Contracts $\S 629$ (rev. ed. 1936); Rest., Contracts $\S 230$ (1932). 
is to say: words are unambiguous if the linguistic rules holding at the time and place in which the words were used are sufficiently well determined so that it is clear in what sense anyone using such words at such time and place would have reason to suppose another person understood them. The dictum of the court in the Inman or Comptograph cases, then, gives us the following information:

The principle that, when the terms of an agreement have been intended in a different sense by the parties, that sense is to prevail against either party in which he had reason to suppose the other party understood it, has no application to contract promises couched and framed in words such that, for conditions similar in essentials to those of the actually contracting parties, the sense in which one person would have reason to suppose another person understood those words is, to an adequate degree of certainty, already determined.

The standard of reasonable expectation, in other words, is not to be applied to agreements to which it has already been successfully applied.

That the restriction of the "secondary" standard to "ambiguous" writings is in fact thus trivial is confirmed by the language of the cases. In Corn Exchange Nat'l Bank \& Trust Co. v. Taubel, e.g., the court is painfully involved in the endeavor to follow the distinctions made by Williston and the Restatement. The passage relevant to the present question reads as follows:

The standard of interpretation of an integrated agreement supported by the weight of modern authority, is the meaning that would be attached to the integration by a reasonably intelligent person acquainted with all operative usages and knowing all the circumstances prior to and contemporaneous with the making of the writing, other than oral statements by the parties of what they intended it to mean, except where it produces an ambiguous result, or is excluded by rule of law establishing a definite meaning. .... This has been termed a primary rule of interpretation which is always applicable, whether the writing seems clear or ambiguous..... The underlying theory is that as all language will bear "some different meanings," evidence of surroundings is always admissible in the interpretation of integrated agreements, but not for the purpose of giving effect to an intent at variance with any meaning that can be attached to the words. . . . But, however this may be, the propriety of admitting evidence of extrinsic facts, where the meaning of the instrument is not clearly apparent, cannot be gainsaid. Where, as here, general or indefinite terms are employed in the agreement, the court may look into the attending circumstances, and avail itself of such light as they may afford in ascertaining the true meaning of the language so used. .... In such a situation the Court must regard the relation of the parties and the circumstances under which the contract was made, and the objects which the parties were thereby striving to accomplish. Such an inquiry is not for the purpose of changing the writing, but to secure light by which to ascertain its actual significance. . . . . It must always be kept in mind that, in an action on the contract, such evidence is admissible only for the purpose of interpreting the writing - not for the purpose of modifying or enlarging or curtailing its terms, but to aid in determining the meaning to be given to the instrument. 
So far as the evidence tends to show not the meaning of the writing, but an intention wholly unexpressed in the writing, it is irrelevant..$_{3}$

The only difference that might be said to subsist between the standards occurring on the two sides of the fence here laboriously erected is that on the one side "oral statements by the parties of what they intended to mean" are explicitly excluded, whereas on the other side there is a reference to "the objects which the parties were thereby striving to accomplish." That apparent reference to actual intent, however, is clearly negated by the further qualification that "so far as the evidence tends to show not the meaning of the writing, but an intention wholly unexpressed in the writing, it is irrelevant." It is such meaning as could, under the circumstances, be reasonably attached to the writing that is sought in all cases; to say that a writing is ambiguous simply means that it is more difficult-or that a greater range of data is required-to indicate for this writing than for some others what its language might reasonably be expected to mean. But what Williston calls the secondary standard for the first class of contracts is in fact the primary standard for the second class; and if it is difficult to find a distinction between those two standards within the first class of contracts, one may at least suspect the clarity of the distinction as between the two classes.

As a matter of fact both the general statements of the two standards and the maxims cited in the cases seem rather strikingly to collapse into one principle with inessential variants in formulation. Consider Williston's formulation of the various standards. In contracts of the second class the standard is one "of reasonable expectation, which would attach to words or other manifestations of intention the meaning which the party employing them should reasonably have apprehended that they would convey to the other party." ${ }^{64}$ Now the application of such a standard will result, under some circumstances, in giving to language its general or normal meaning. Sometimes, on the other hand, a local or trade or technical or otherwise limited meaning may prevail, indeed, an even narrower meaning might seem to define, for certain words, what a person would "reasonably expect another to understand" by them, but on the one hand "mutual" meanings are generally excluded on grounds of policy, and on the other hand it seems clear that they would in any case be admitted, not in so far as the parties actually intended to employ such meanings, but in so far as such meanings correspond to the interpretation which a third party under the same circumstances could reasonably attach

${ }^{6}$ II $_{3}$ N.J.L. 605,609, I 75 Atl. 55, 57 (r935).

${ }^{64} 3$ Williston, Contracts $\$ \S 603,605$ (rev. ed. 1936 ); Rest., Contracts $\$ \S 227,233$ (1932). 
to the language used. In contrast to this relatively flexible standard, then -which might result in the interpretation of language in its general, local, or sometimes in a mutual or individual sense-we have for the first class of contracts the rule that only one of the above meanings, namely the local one, is to be given. For contracts in which there is an integration or a writing is required by law, the standard is one "of limited usage, which would attach the meaning given to language in a particular locality, or by a sect or those engaged in a particular occupation, or by an alien population or those using a local dialect."65 This standard, then, gives to language one of the meanings which could be given to it under the less specific standard of reasonable expectation. But how, in fact, does such a standard operate? In the first place, Williston qualifies the statement of the principle by the assertion that the difference between normal and local standard is one of degree. ${ }^{66}$ And it is clear that where the use of the more general meaning causes no difficulty, the court will not go out of its way to look for some dialect or trade usage which must be substituted for what is for all concerned a perfectly satisfactory interpretation. If A contracts to buy B's white house, and there is no evidence that white house is in the language of the real estate business or the dialect of A's or B's sect or locality anything but what is usually called white in the normal English language, the court will not strain itself to discover a usage in the textile trade or some other place or profession whereby "white" means dark gray. Where it happens to be the normal rather than a peculiarly local meaning of words that defines what the party employing such words should reasonably have apprehended that they would convey to the other party, it is surely such a general meaning that will prevail. Conversely, moreover, the Restatement in its discussion of usage declares that usage is inoperative "if either party knows or has reason to know that the other party has an intention inconsistent with the usage." ${ }^{267}$ That is to say: if, and only if, evidence of usage contributes to the determination of the meaning which a person employing certain words could reasonably have expected them to convey to another person, is such evidence relevant. The local meaning is given to words if, and only if, such meaning can be reasonably given; where that is not the case the general meaning is used-or even, where policy allows, a mutual meaning. To say, in other words, that a "standard of limited usage" is employed for agreements where a writing has been adopted, is to say that in many cases the application of the standard of reasonable expectation has the

${ }^{65} 3$ Williston, Contracts $\$ \S 603,607$ (rev. ed. I936); Rest., Contracts $\$ \S 227,230$ (I932).

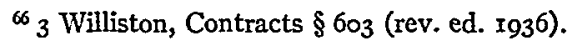
${ }_{67}$ Rest., Contracts $\$ 247$ (1932). 
result of attaching "the meaning given to language in a particular locality, or by a sect or those engaged in a particular occupation, or by an alien population or those using a local dialect." The relationship is evident in Williston's own statement: "In applying the standard of limited usage to integrations, the inquiry of the court should be-What was the meaning of the writing at the time and place it was made between persons of the kind or class who were parties to it?"68 In other words: what, under these circumstances of linguistic custom, would a reasonable person have expected another to understand by the language he employed? There thus appears to be no need, as Williston finds, for contradicting such unrestricted expressions of the standard of reasonable expectation as the cases actually present. In Gates v. Megargel, for instance, it is said that "a writing is to be interpreted in the sense in which the maker knew or had reason to know it would be understood by the party to whom he tendered it."'9 Similarly, it was said by Blackburn, J., in Fowkes v. Manchester etc. Ass'n:

There are rules of construction which, though they may be cited on both sides, furnish principles for our guidance; and one of those rules is, that in all deeds and instruments the language used by one party is to be construed in the sense in which it would be reasonably understood by the other. ${ }^{\circ}$

Such maxims-and especially the latter, which omits any reference to actual understanding-seem to express simply and adequately the standard actually applied to all agreements. Nor do they contradict the dicta which announce a preference for the local as against the normal standard, since, as we have seen, such a preference results, in a given case, from the specific application of the more general principle.

This conclusion is unfortunately obscured, it seems to me, by the addition to Wigmore's four "standards" of an additional standard which is in fact of a radically different order. ${ }^{7 x}$ It would in fact be preferable to

${ }^{68} 3$ Williston, Contracts $\$ 617$ (rev. ed. I936).

69 Gates v. Megargel, 266 Fed. 8rr, 8I8 (C.C.A. 2 d r920).

${ }^{70} 3$ B. \& S. $9 \mathrm{r} 7,929$ (I863) (It may be objected that Blackburn is here stating the standard of reasonable understanding, as distinguished by the Restatement $\$ 227$ from the standard of reasonable expectation. That distinction seems, however, to be a very artificial one-for surely, since "reasonable expectation" is expectation of "reasonable understanding," it may be said that to construe the language of one party in the sense in which it would reasonably be understood by a second party in effect is the same as to construe it in the sense in which the first party should reasonably expect that it would be understood by the second party. The relational field to be analyzed is the same, whether the relation of reasonable expectation or its converse, reasonable understanding, be employed as the instrument of analysis.) McMillin v. Titus, 222 Pa. 500, 72 Atl. 240 (I909); Ardis v. Grand Rapids Ry. Co., 200 Mich. 400, 167 N.W. 5 (IgI8).

${ }^{3 x} 3$ Williston, Contracts $\S 603$ (rev. ed. 1936 ); 5 Wigmore, Evidence $\S 246$ I (2d ed. I923). 
reserve the title of "standard" for the additional principle, and to call Wigmore's "standards" either so many "languages" or so many types of "meaning" discoverable by the use of one standard. It is not always apparent, from words alone, in what language those words occur. The string of signs "God Mad," for instance, might on the face of it be proclaiming in head-line jargon a strange kind of relation between deity and insanity or bad temper. The same string of signs, appearing on the window of a Danish restaurant, has the same meaning as the English words "Good food." Similarly, it is sometimes the case that within a given natural language such as English the same signs have several different meanings in different local or professional or sectarian or individual languages. And in asking what a person using words at a given time and place might reasonably expect another person to understand by those words, one is asking, first of all, what language it is in which those words were used-whether it is the general language English, or a language common to a certain trade or locality or other well-established group, or a language common to two or several individuals, or the language of one individual alone. The meaning to be reasonably attached to words is, obviously, the meaning attached to them in the language in which they are used, not the meaning attached to them in some other language. The first step in the search for the meaning reasonably to be attached to signs, therefore, is the determination of the language to which the signs in question actually belong. Only after that step is it possible, by the formulation of the dictionary and rules of that language, to proceed to the actual determination of specific meanings-which will, of course, be relative to the language in which, by the first step, the words have been found to occur. What the standard of limited usage tells us, then, is, first, that the language spoken in written instruments is often a local or otherwise limited rather than a general one; and secondly, that, in so far as that is the case, the meaning given to words by the application of the standard of reasonable expectation will often be, correspondingly, local or limited rather than "normal."

\section{III}

The need for a multiple standard, it was suggested at the opening of the preceding section, is sometimes presented as a function of the "wellsettled" rule that parol evidence cannot be introduced to alter the terms of an integrated agreement. We discovered, however, not only that it was extremely difficult to locate satisfactorily a clear line between the two classes of contracts thus created; but that when the parol evidence rule is taken to exclude evidence of actual intention rather than all ex- 
trinsic evidence it seems merely to be excluding what is irrelevant in any case for purposes of interpretation. It thus appears that the problem is created not so much by the exclusion of evidence of intent in certain cases as by the insistence of the courts that actual intent has something to do with the matter in the first place; and it would be well, therefore, to examine more explicitly, in conclusion, the dictum that "the object of construction is to ascertain the intention of the parties." $7^{2}$

Language is, as Wigmore says, in some sense "subjective and personal."73 The question is whether it is the subjective or personal aspect of language with which the law is concerned. And from the repeated assertions that the great object of interpretation is to get at the intent of the parties it would certainly appear that it is. Even a theory of interpretation as "objective" as Williston's contains some hints that, while unfortunately courts are obliged, for the sake of certainty, to construe contracts in terms of expressed not actual intention, it is really actual intent that is ultimately important. ${ }^{74}$ But the most emphatic statement in this direction is Wigmore's:

So long as men are allowed to grant and contract freely, and so long as the law undertakes to carry out those acts by enforcement, just so long must the standard of interpretation continue to be mobile, subjective, and individual. Mr. Justice Brook once thought it "barbarous" that a man should "be assured that whatever words he made use of, his meaning only should be considered." But as the law of today has broken with his premise, so it must break with his conclusion. The ordinary standard, or "plain meaning," is simply the meaning of the people who did not write the document. The fallacy consists in assuming that there is or even can be some one real or absolute meaning. In truth, there can only be some person's meaning; and that person, whose meaning the law is seeking, is the writer of the instrument. ${ }^{75}$

\section{Or again:}

There is no transaction whatever in which, for some idea or other, the parties do not use words in a sense of their own. Having themselves locked up the idea in the words, themselves must furnish the key to unlock it. ${ }^{76}$

It should be evident, however, from the considerations of the preceding section, that if it is the purpose of the law to discover such subjective meanings, it is a purpose the achievement of which is in practice never even attempted. For even in cases beyond the magic circle of the parol evidence rule the court endeavors to discover not what the parties meant

72 Domeyer v. O'Connell, 364 Ill. 467,4 N.E. (2d) 830 (I937).

${ }^{73} 5$ Wigmore, Evidence $\S 2462$ (2d ed. r923).

${ }^{74} 3$ Williston, Contracts $\S 608$ (rev. ed. 1936 ).

${ }^{75} 5$ Wigmore, Evidence $\S 2462$ (2d ed. I923).

${ }^{76} I d$., at $\$ 2465$. 
to say but what they can reasonably be understood to have said. That is clear, for example, in the opinion in the Corn Exchange case cited above: even where there is "ambiguity" it is a standard of reasonable expectation, not of subjective intention that is employed. It is clear even through the vestiges of subjective language in a statement like that in Woburn Nat'l Bank v. Woods:

A contract involves what is called a meeting of the minds of the parties. But this does not mean that they must have arrived at a common mental state touching the matter in hand. The standard by which their conduct is judged and their rights are limited is not internal, but external. In the absence of fraud or incapacity, the question is: What did the party say and do? "The making of a contract does not depend upon the state of the parties' minds; it depends on their overt acts." It is elementary in the law governing contracts of sale and all other contracts, that the agreement is to be ascertained exclusively from the conduct of the parties and the language used when it is made, as applied to the subject-matter and to known usages. The assent must be mutual, and the union of minds is ascertained by some medium of communication. A proposal is made by one party and is acceded to by the other in some kind of language mutually intelligible, and this is mutual assent. A person cannot escape the natural and reasonable interpretation which must be put on what he says and does, by showing that his words were used and his acts done with a different and undisclosed intention. .... It is not the secret purpose, but the expressed intention, which must govern in the absence of fraud and mutual mistake. A party is estopped to deny that the intention communicated to the other side was his real intention. ${ }^{77}$

But the principle is most clearly stated, perhaps, in the opinion of Blackburn cited above:

If, whatever a man's real intention may be, he so conducts himself that a reasonable man would believe that he was assenting to the terms proposed by the other party, and that other party upon that belief enters into the contract with him, the man thus conducting himself would be equally bound as if he had intended to agree to the other party's terms. ${ }^{78}$

To assert as the object of construction, however, what is never actually sought in construction is to establish between theory and practice a most inconvenient relation, necessitating numerous apologies and reconstructions which would be eliminated were the theory built, initially, to account for the practice. As it is, in almost every statement of the rules of interpretation, a sort of hankering after actual intent seems somewhere to insinuate itself, with the effect of confusing what looked like a reasonably clear principle. "Our guide," says Cardozo in Bird v. St. Paul $F$. \& M. Ins. Co., "is the reasonable expectation and purpose of the ordinary business man when making an ordinary business contract. It is his

7777 N.H. $7_{72}$, I77, 89 Atl. 49I, 492 (I9I4).

${ }^{78}$ Smith v. Hughes, L.R., 6 Q.B. 597,607 (187I). 
intention, expressed or fairly inferred, that counts."79 So far, so good. But he goes on to say: "The inquiry for us is how far the parties to this contract intended us to go." The reasoning seems to be somewhat as follows: we want to know the intention of the parties-just when they actually expected the word in question to apply; but the parties are business men, presumably reasonable business men; therefore to get at their intention we look for the linguistic usage of the reasonable business man, which will reflect his intention and thus indicate to us indirectly the intention of the parties-since they are likewise reasonable business men. As a matter of fact the situation is almost the reverse of that just described: we want to know the meaning of the words used; the parties are business men, therefore we assume that the language used here is that of business men; and we proceed to consider the rules of business language in order to determine, what, in that language, the words in question mean. The circumstances of the actual parties serve, for purposes of interpretation, to identify the language in which the instrument is written; once that is determined, the problem is simply how a reasonable man speaking that language would understand the words in question. The actual subjective intention of the parties has, for the purpose of construction, simply nothing to do with the matter. From this point of view, therefore, a reference to the sense in which a party "knew or had reason to know" his language would be understood is either redundant or erroneous. It is solely what he had reason to know that is relevant.

Significant symbols have at least three aspects. There is the subjective, personal meaning of words of which Wigmore speaks: that is, the idea, image, or feeling evoked in the individual mind by a certain symbol. There is the empirical or semantical meaning of words, that is, their reference to external things or events. And there is the formal meaning of words, that is, their systematic connection with other words of the given language. ${ }^{80}$ Problems concerning the third factor may arise in the field of interpretation when there are apparent contradictions in an instrument needing resolution; for in general they are co-extensive with the problems usually called "logical." But it is, as the much-cited case of Doherty v. Hill suggests, ${ }^{8 x}$ the second kind of meaning that is of crucial

${ }^{79} 224$ N.Y. 47,5 I, I20 N.E. 86,87 (Igr8). The question is one of the interpretation of the phrase "proximate cause" in a fire insurance policy.

${ }^{80}$ This division corresponds in part to the analysis of language of C. W. Morris. See: Morris, Logical Positivism, Pragmatism and Scientific Empiricism (I937), and Foundations of the Theory of Signs, in Foundations of the Unity of Science (1938). Only a portion of his "pragmatic" dimension is included in the "psychological" or subjective aspect of symbolism referred to here.

${ }^{8 \mathrm{r}}$ I44 Mass. 465 , II N.E. $58 \mathrm{r}$ (I88r). 
importance for interpretation. And the first is, in contrast, a matter of little if any importance for the law. That conclusion, in direct contradiction to Wigmore's theory, is stated in Justice Holmes' article on "The Theory of Legal Interpretation," which presents, in its entirety, a clear and authoritative answer to the perplexities raised at the opening of this paper. Speaking of the admission of extrinsic evidence to aid in the interpretation of a document, Justice Holmes asks:

Is this trying to discover the particular intent of the individual, to get into his mind and to bend what he said to what he wanted? No one would contend that such a process should be carried very far, but, as it seems to me, we do not take a step in that direction. It is not a question of tact in drawing a line. We are after a different thing. What happens is this. Even the whole document is found to have a certain play in the joints when its words are translated into things by parol evidence, as they have to be. It does not disclose one meaning conclusively according to the laws of language. Thereupon we ask, not what this man meant, but what those words would mean in the mouth of a normal speaker of English, using them in the circumstances in which they were used, and it is to the end of answering this last question that we let in evidence as to what the circumstances were. But the normal speaker of English is merely a special variety, a literary form, so to speak, of our old friend the prudent man. He is external to the particular writer, and a reference to him as the criterion is simply another instance of the externality of the law. ${ }^{82}$

It remains to reconsider briefly our initial questions, as suggested by the contradictory dicta of the Illinois cases. ${ }^{83}$ The first conflict, between the maxim that "the great object is to arrive at the intention of the parties" and the rule excluding evidence of such intention, is resolved by the denial of one member of the inconsistent pair. The second question concerned the relation between the principle that all extrinsic evidence is excluded in construing a contract, and the principle that the court will always endeavor, by extrinsic evidence, "to place itself in the position of the parties." Here again the former principle seems, by the weight of authority, to be flatly wrong. It should be added, however, in the light of our conclusions, that the alternative rule likewise needs modification in the direction of great objectivity. "In the construction of contracts (not for the purpose of ascertaining the intention of the parties, but) for the purpose of ascertaining the empirical meaning of the language used by the parties, the court will endeavor, by extrinsic evidence of such facts as the parties had in view, to place itself as nearly as possible in their position, so that it may understand the language used (not in the sense intended by them, but) in the sense in which a normal speaker of English placed in such a position would understand such language or expect another to understand it." 184

\& 12 Harv. L. Rev. 4 I7 (I899).

$8_{3}$ Section $I$, supra.

${ }^{84}$ See Weger v. Robinson Nash Motor Co., 340 III. 8I, 91, I 72 N.E. 7, II (I930). 